\title{
La minificción ya no es lo que era: una aproximación a la literatura brevísima
}

\author{
Mini-fiction is not What it Used to Be: An Approach to Extremely Short Literature \\ A minificção não é más o que era: aproximação da brevíssima literatura
}

\section{Violeta Rojo}

UNIVERSIDAD SIMÓN BOLÍVAR, CARACAS, VENEZUELA

Profesora titular de la Universidad Simón Bolívar. Doctora en Letras,

Universidad Simón Bolívar. Individuo correspondiente de la Academia

Norteamericana de la Lengua Española. Ha publicado Mínima

Expresión: una muestra de la minificción venezolana (Caracas:

Fundación para la Cultura Urbana, 2009), Breve manual (ampliado)

para reconocer minicuentos (Caracas: Equinoccio, 2009); con Héctor

Abad Faciolince y Carlos Leáñez Aristimuño, Antología de la novísima narrativa breve hispanoamericana (Caracas: Grijalbo/Unión Latina, 2008); Teresa Carreño (Caracas: Biblioteca Biográfica Venezolana, 2005), El minicuento en Venezuela (Bogotá: Universidad Pedagógica Nacional, 2004 y 2008) y Breve manual para reconocer minicuentos (Caracas: Fundarte/ Equinoccio, 1996 y México: Universidad Autónoma Metropolitana, 1997). Correo electrónico: vrojo@usb.ve 


\section{Resumen}

Los estudios sobre la minificción comenzaron en los años 80 . Hoy, este género literario, anteriormente visto como una excepción literaria o un divertimento, tiene cultores, teóricos, practicantes y miles de páginas dedicadas a su análisis. Más de 30 años después de los primeros estudios sobre minificción, es hora de hacer una revisión del género, sus denominaciones, definición, características, historia, adscripción genérica, longitud, etc. En este artículo, se revisan las teorías más importantes, mostrando diferencias y semejanzas, acuerdos y desacuerdos.

Palabras clave: minificción; teoría literaria; historia de la minificción; géneros literarios; literatura latinoamericana

\section{Abstract}

Studies on mini-fiction started during the $80 \mathrm{~s}$. Today this literary genre, previously seen as a literary exception or amusement, has enthusiasts, theorists, practitioners, and thousands of pages dedicated to its analysis. Over 30 years later after the first studies on mini-fiction, it is time to make a review of the genre, its names, definition, characteristics, history, genre affiliation, length, etc. This article reviews the most important theories, showing differences and similarities, agreements and disagreements.

Keywords: mini-fiction; literary theory; history of mini-fiction; literary genres; Latin American literature

\section{Resumo}

Os estudos sobre minificção começaram nos anos 80 . Hoje, este gênero literário, anteriormente visto como exceção literária ou divertimento, tem cultores, teóricos, praticantes e mis de páginas dedicadas à sua análise. Após mais de 30 anos dos primeiros estudos sobre minificção, estamos na hora de fazer revisão do gênero, suas denominações, definição, caraterísticas, história, atribuição genérica, comprimento, etc. Neste artigo, revisitam-se as teorias mais importantes, mostrando diferenças e semelhanças, acordos e desacordos.

Palavras-chave: minificção; teoria literária; história da minificção; gêneros literários; literatura latino-americana

\section{Cómo citar este artículo:}

Rojo, Violeta. "La minificción ya no es lo que era: una aproximación a la literatura brevísima". Cuadernos de Literatura 20.39 (2016): 374-

386. http://dx.doi.org/10.11144/Javeriana.cl20-39.mnel 
¿QUÉ ES LA MINIfICGIÓN? ¿Es un género ${ }^{1}$ o un subgénero? ¿Tiene una longitud precisa? ¿Cuáles son sus características? ¿Cuál es el nombre más adecuado? ¿Cuál es su historia? ¿Es una forma moderna? ¿ ${ }_{\mathrm{i}}$ Se sabe dónde y cuándo apareció? Como suele suceder con las expresiones artísticas, hay muchas respuestas distintas, unas veces contradictorias, otras coincidentes, todas igualmente bien argumentadas, pero no hay más que algunos consensos.

Podríamos ir por la vía simple y decir que la minificción es una forma literaria muy breve, narrativa y ficcional. Su longitud es variable, pero no debería tener más de una página impresa, o sea unos 1500 caracteres. Su nombre se debate entre micro y minificción, mini y microrrelato, micro y minicuento y variaciones que implican su escasa longitud y su carácter vinculado a la narración ficcional. Sus características implican elegancia escritural (porque en tan poco espacio debe utilizarse la palabra justa); hibridez, proteísmo y des-género (porque cambia de forma y de género); uso de la intertextualidad (porque de esa manera el lector conoce los antecedentes y el autor puede dar por sabidas muchas cosas), así como el uso de la parodia, la ironía, la elipsis y el humor. Se considera un género que nació en Latinoamérica, de donde vienen sus pioneros: Rubén Darío, Julio Torri, Leopoldo Lugones y Juan José Arreola, entre otros. También en Latinoamérica fue donde comenzó a desarrollarse con gran ímpetu a partir de Augusto Monterroso, Jorge Luis Borges y Julio Cortázar, sobre todo en los años 70 y de manera ubicua desde los años 90 del siglo pasado hasta ahora, en la que se dan ejemplos en muchas lenguas y países.

Ojalá fuera tan fácil. Todo lo recién afirmado podría verse de otra manera menos sencilla en el momento en el que comienza a analizarse en profundidad. El resultado implicará que las certezas desaparecen; que puede que sea un nuevo género o posiblemente no; que no se sabe cuándo comenzó, que sus características no están claras, que el nombre tampoco y que los padres son muchísimos. Incluso, si existe como género independiente es porque los teóricos han decretado su existencia y a partir de algún momento los escritores han desarrollado ejemplos que confirman a los estudiosos.

Tantos titubeos tienen su razón de ser. Si hay un género que rechaza los absolutos, las certezas, las afirmaciones contundentes es este que nos ocupa. Su longitud es variable dentro de su corta extensión; su expresión como género es complicada, ambigua, inaprensible, elusiva; sus características son pocas o demasiadas, dependiendo de quién las enumere; su definición es poco clara, su nombre varía de país a país, de autor a autor. Lo que se puede hacer son propuestas, acercamientos, su-

1 Se usa género literario en el sentido tradicional del Diccionario de la Academia Española: "Cada una de las distintas categorías o clases en que se pueden ordenar las obras literarias". 
gerencias, dudas, tanteos. Cualquier certidumbre queda pronto descartada ante un nuevo ejemplo que niega la presuposición anterior. Si lo típico de la minificción es lo elusivo y ambiguo, los ordenamientos a los que somos tan dados en la academia terminan siendo restrictivos y poco veraces. Además, todo con la minificción pareciera un work in progress, de manera que lo que hoy nos parece el inicio, tiempo después, con nuevos hallazgos, demuestra ser algo a mitad del camino.

Por supuesto, esta indeterminación ocasiona muchas trabas y malentendidos. Ha pasado de no existir, a ser despreciado por ser algo raro, a estar de moda, a ser omnipresente, a ser una extravagancia y, otra vez ser desdeñado esta vez por ser demasiado común. Después de todo este tiempo algunos aún no lo juzgan como literatura y a pesar de los muchos congresos internacionales y nacionales, las publicaciones, las editoriales dedicadas al tema, todavía hay quienes lo califican como una excentricidad cuando son misericordiosos, o algo sin importancia que es perfecto para holgazanes de la escritura y la lectura. Y todo esto tiene también que ver con la brevedad, porque pareciera muy corto para ser importante. Pero al ensayo en sus inicios lo vieron como algo raro, la poesía sin métrica ni rima fue reputada también refugio de vagos y la polémica sobre las artes plásticas no figurativas prosigue en pleno siglo XXI.

La brevedad también conlleva su aparente facilidad de escritura (no es igual escribir una novela, está claro). Eso hace que muchos piensen que cualquier pequeña ingeniosidad vale como muestra del género, para desesperación de analistas y minicuentistas serios. Los generosos premios que se ofrecen en los concursos del área (teniendo en cuenta el número de caracteres), hacen que tengan decenas de miles de concursantes, que "prueban a ver" si su textito funciona. La brevedad, entonces, que tanto esfuerzo implica para los cultores escrupulosos, resulta también en la banalidad de algunas propuestas y el abaratamiento del género. Al haber crecido el corpus de manera exponencial, se hace complicado conocer las propuestas de cada país y de cada lengua. La abundancia, por otra parte, se convierte en una selva en la que se hace difícil encontrar joyas. Pero sobre todo, la profusión implica también tal amplitud de propuestas que se hace difícil tener una visión más o menos clara de lo que se produce.

$\mathrm{Y}$ aquí pasamos a algo importante. Al ser tan ambiguo, movedizo y resbaloso ¿quiere decir que todo vale? Pues no. Las minificciones deberían ser pequeñas obras de arte, y eso, como bien sabemos, es siempre muy difícil de lograr.

\section{La historia de lo mínimo}

Como en el chiste del profesor, podríamos decir que la minificción comenzó por no existir, aunque la escritura de miniaturas literarias es ancestral. Está en 
las Misceláneas griegas y romanas, los Makura no Soshi(Libros de la almohada) japoneses, de alrededor del año 1000 que pertenecen al género Zuihitsu (textos breves, escritos a vuelapluma) y los Commonplace books medievales y renacentistas ingleses. También hay brevedades en lo que los ingleses llaman Hodgepodge (miscelánea), los Gemeinplätze alemanes, los Lieux Communs franceses y los Zibaldone italianos del siglo XIX (Rojo, "La tradición de lo novísimo"). Francisca Noguerol ("Líneas de fuga") lo vincula a los Dietarios españoles, Laura Pollastri a las inscripciones en las estelas funerarias de la antigüedad, David Lagmanovich (El microrrelato: teoría e historia) al haiku, Paul Dávila al koan, y así podríamos seguir hasta el infinito. A partir de allí se da un salto de varios siglos. Lagmanovich (El microrrelato: teoría e historia) considera que los Pequeños poemas en prosa de Charles Baudelaire son un precursor importante. Entre los antepasados están también Ambrose Bierce y Nataniel Hawthorne con sus Cuadernos, dice Graciela Tomassini ("Ambrose Bierce" y "Escrituras privadas"). Juan Armando Epple ("Orígenes de la minificción") nombra a Aloysius Bertrand, Villiers de L'Isle, Oscar Wilde, Jules Renard, Lord Dunsany, Franz Kafka, George Loring Frost y a I.A. Ireland. Y allí hay otro salto, esta vez a los latinoamericanos del siglo Xx: Rubén Darío, Alfonso Reyes, Julio Torri, José Antonio Ramos Sucre, Luis Vidales, Vicente Huidobro y Ernesto Lugones, entre otros. Stella Maris Colombo ("Giovanni Papini: un antecedente desprestigiado") hace una compilación de los distintos antecedentes de varios estudiosos, en los que incluye al ya mencionado Franz Kafka, a Bertolt Brecht y Ernest Hemingway (para Lagmanovich), el ya nombrado Ambrose Bierce (para Tomassini) y Giovanni Pappini (para Colombo, Roas y Anderson Imbert). Según Dolores Koch ("El micro-relato en México"), el iniciador fue el mexicano Julio Torri. David Lagmanovich y Laura Pollastri han estudiado en profundidad el precedente de las vanguardias latinoamericanas y la literatura modernista en el género. Por supuesto, las Greguerías de Ramón Gómez de la Serna deben ser tomadas en cuenta. Pero allí hay otro salto más hasta 1955, cuando aparece Cuentos breves y extraordinarios de Jorge Luis Borges y Adolfo Bioy Casares. Esta es valorada como la primera antología de un género que todavía no existía como objeto de estudio y recoge ejemplos de textos brevísimos que ahora son catalogados como minificciones. Y poco después, en 1959, Augusto Monterroso publica el más famoso minicuento de todos los tiempos, "El dinosaurio", uno de los textos de Obras completas (y otros cuentos). A partir de allí es fácil seguir la lista de autores que comienzan a desarrollar una literatura brevísima, desde el mexicano Juan José Arreola, el colombiano Álvaro Cepeda Zamudio, los argentinos Marco Denevi y Enrique Anderson Imbert, el cubano Virgilio Piñera, el venezolano Alfredo Armas Alfonzo, y muchos más. Y del furor 
de los años 70, otro salto a los años 90 - aunque algunos autores dicen que es más bien en los 80- cuando de nuevo el género se desarrolla con multitud de escritores latinoamericanos, españoles, de lengua inglesa, brasileros, coreanos... Y otro salto, esta vez cuantitativo, con el nuevo siglo y el auge de las redes sociales. La minificción tiene la longitud más amable para ser leída en blogs, Twitter, Facebook, Tumblr y demás, por lo que en la red hay miles de páginas dedicadas a esta forma. Incluso, ya hay autores (Raguseo, Zambrano) desarrollando una teoría literaria específica sobre la tuiteratura, esto es, la minificción en no más de 140 caracteres. Con esto hemos llegado a tal omnipresencia de los textos brevísimos que, como dice Julia Otxoa, "levantas una piedra, un lagarto, una miga de pan y te encuentras un[o]" ("Breve entrevista"). Como con la victoria, la minificción tiene muchos padres y, como con los héroes, también tiene muchos pueblos que reclaman ser su cuna.

Como es evidente con este intento de sistematización histórica, no hay un desarrollo preciso y continuado, sino estallidos desordenados en los que se mezclan muchos géneros, autores que escriben textos brevísimos en algún momento pero no siempre, textos más o menos cortos, modas que pasan, experimentaciones que dan paso a otras búsquedas y, en otros autores, dedicación exclusiva al género.

El problema con las historias es que siempre son relativas, así es que tal cantidad de antecedentes muestra que, como siempre en los fenómenos literarios, las influencias son muchas, múltiples y personales. Todos los autores citados habrán sido precedente para alguno, mas no para otro. Quizás hay un Zeitgeist que tiene que ver con la brevedad, pero en esas mismas épocas se dieron ejemplos de textos narrativos de muy largo aliento, de manera que cualquier vinculación temporal con la minificción no puede ser sino limitada. Por otra parte, tantos fundadores me hacen pensar que quizás la respuesta sea más sencilla. La literatura brevísima ha existido desde el principio de los tiempos de la escritura, y se da sea en forma de aforismo, alegoría, apólogo, cuadro, caso, enxiemplo, epigrama, estampa, fábula, parábola, proverbio, sentencia, viñeta y la infinita variedad de antiguos textos literarios muy cortos. ¿Y cuál sería la diferencia con la minificción? Ninguna o mucha. La minificción es literatura del siglo XX en adelante, y tiene las mismas diferencias con sus antecesores que la que tiene la novela, la poesía o el ensayo del siglo XX y XXI con sus antecesores.

El término minificción (y sus múltiples variaciones) comenzó a utilizarse hace poco tiempo, lo que implica que la forma literaria a la que damos tal nombre se puede pensar que fue creada por los estudiosos del área, que le hemos dado forma teórica, conformando en un género literario lo que antes eran distintas formas mínimas que los escritores desarrollaban sin preocuparse de la taxonomía. 


\section{La cuestión del nombre}

Pocos géneros tienen tantos apelativos: arte conciso, brevicuento, caso (aplicado a la narrativa breve de Anderson Imbert), cuasicuento, cuentín, cuento breve, cuento brevísimo, cuento corto, cuento cortísimo, cuento diminuto, cuento en miniatura, cuento escuálido, cuento instantáneo, cuento más corto, cuento rápido, fábula, ficción de un minuto, ficción rápida, ficción súbita, hiperbreves, historias mínimas, microcuento, microficción, microrrelato, microtexto, minicuento, minificción, minitexto, nanocuento, relatillo, relato corto, relato mínimo, relato microscópico, rompenormas, texto ultrabrevísimo, ultracorto, varia invención (para la de Juan José Arreola), textículo, entre muchos otros.

Los que más se usan son los términos minificción, microrrelato, minicuento y microficción. La distinción implica que es un cuento muy corto, un relato muy breve o una forma ficcional (no necesariamente un cuento o un relato) mínima. Si bien la ausencia de un nombre preciso desespera algunos, el que no haya un nombre específico y que tenga tantos apelativos es perfecto para una forma literaria ambigua e híbrida. Si bien se ha considerado que la forma solo es factible si se narra una historia, hasta en eso hay dudas. Las historias en la minificción no están necesariamente explicitadas, sino que la participación del lector es la que completa lo propuesto por el autor. En ese caso, la historia en algunas ocasiones se esboza y el lector la integra. Por eso Tomassini y Colombo, en el 2013, denominan a la minificción como una "máquina de pensar".

$\mathrm{Al}$ revisar la historia del género podemos comprobar que la nomenclatura minificción/microrrelato/minicuento es reciente. En los diarios de Alfredo Bioy Casares, cuando habla de la génesis de la antología Cuentos breves y extraordinarios, dice que Borges y él escriben cuentos o cuentitos. Italo Calvino, cuando habla de "El dinosaurio" de Augusto Monterroso, lo llama cuento. Según Javier Perucho (Perucho), el término microrrelato lo utilizó en primer lugar José Emilio Pacheco en su columna Inventario a partir de 1977. Dolores Koch, posiblemente la primera teórica del género, utilizó micro-relato a partir de 1981. En los años 70 también se usaba minicuentos. Minificción se hizo más usual a partir del Primer Coloquio Internacional en México en 1998. Yo utilicé el término minicuento en 1992 porque me parecía que era un cuento muy corto, con todas las características de la forma canónica, con la excepción de la longitud. Sin embargo, ahora no tengo tal certeza, así que prefiero minificción. Si bien hay estudios que establecen diferencias entre uno y otro en razón de sus características, siendo la minificción el término paraguas que acoge a los relatos y cuentos muy cortos, creo que tal especificidad solo complica. 
En asuntos de nomenclatura quizás es más adecuada la teoría de William Shakespeare: "What's in a name? that which we call a rose/By any other name would smell as sweet" (Romeo y Julieta, II, 2).

\section{La longitud, la definición y las características}

Como ya se afirmó anteriormente, la única convicción que tenemos sobre este tema es que la minificción es una forma literaria muy breve. Y esa brevedad es categórica. Todo en la minificción termina siendo determinado por su longitud. La brevedad es lo que genera muchas de sus virtudes y sus problemas. Al ser tan breve, los ignaros piensan que es fácil, y algunos se largan con total impudicia a escribirla, con resultados lamentables, mientras que otros deciden que el género es lo que falla, y no que lo que falla son los textos escritos en minutos.

Pero, sobre todo, la brevedad ocasiona la longitud del corpus. Por ejemplo, un libro del género puede tener cien textos, cada uno distinto al otro en su manera formal. Al tener una muestra tan increíblemente amplia, hay muchísimos ejemplos diferentes y las excepciones no pueden resolverse con el fácil argumento de que confirman la regla. Son tantas las excepciones que la regla termina por no existir. Eso explica que la caracterización, a menos que sea muy amplia, termina siendo relativa, que lo que se consideran antecedentes terminan extendiéndose hasta el principio de los tiempos y a que sea tan acomodable que es posible terminar encontrando minificciones en cualquier texto.

Por otra parte, la brevedad originará sus características y hará el género: es ella la que provoca el cuidadoso lenguaje, esa necesidad de encontrar la palabra adecuada, porque son pocas las que se utilizan. Al ser breve tendrá que ser desgenerada e intertextual para que el lector tenga referentes e información previa y el autor no deba desarrollar aspectos que da por sabidos; eso también implica que la ironía, la reinterpretación y la parodia siempre estarán cerca; asimismo tendrá que utilizar también un lenguaje muy preciso, no podrá evitar utilizar las elipses y sugerencias. En suma, las características de la minificción estarán vinculadas a los juegos textuales a los que obliga su brevedad.

No hay un número específico ni de caracteres ni de palabras, pero a simple vista debería verse el texto. Lauro Zavala (La minificción bajo el microscopio) establece diferencias entre cuentos cortos (1000 a 2000 palabras), cuentos muy cortos (200 a 1000 palabras), cuentos ultracortos (1 a 200 palabras). Otros autores prefieren no establecer una longitud máxima determinada; para ellos son breves y ya.

Haciendo un recuento de características: para Dolores Koch ("El microrelato en México") son relatos sin introducción, anécdota o acción, sin personajes delineados, ni punto culminante y, por tanto, sin desenlace. Además, apunta, la 
prosa es sencilla, cuidada, precisa y bisémica; utiliza el humor, la paradoja, la ironía y la sátira; rescata formas literarias antiguas y las inserta en formas no literarias. Para Laura Pollastri (Pollastri) sus características serían: humor, plurisemia, intertexto, fragmentariedad, los pactos entre lector y autor. Para Francisca Noguerol ("Microrelato y posmodernidad") son textos escépticos, en los que se recurre a la paradoja, privilegian los márgenes y experimentan con temas, personajes y formatos, son fragmentarios, necesitan la participación del lector, son polisémicos, intertextuales, utilizan el humor y la ironía. Para Lauro Zavala (La minificción bajo el microscopio) tiene cinco características: brevedad, diversidad, complicidad, fractalidad y fugacidad. Nana Rodríguez (Rodríguez Romero) enumera el humor, la ironía y el lenguaje simbólico, lo poético, lo onírico, lo filosófico y lo fantástico y la conexión entre título y contenido como elementos fundamentales.

Podríamos seguir revisando las características que cada estudioso propone y también las que se incluyen en los decálogos de la minificción, pero creo también que, dado el ingente corpus, podríamos encontrar cada vez más características. Mientras más textos se analicen, posiblemente más características se encontrarán.

Si tratáramos de llegar a una caracterización minimalista, quizás podríamos reafirmar que la minificción es breve y de cierta manera ficcional, pero aquí entramos en un problema que escapa de los límites de este texto.

${ }_{\mathrm{i}}$ No es ficcional todo texto escrito? Creo que ya en el siglo XXI sabemos que los límites entre la escritura documental y no-documental son tenues e imposibles de determinar. $\mathrm{i}$ Es de verdad importante la invención argumental o es preferible el texto bien escrito? Cuando Oviedo y Baños dice de la Caracas de 1723 "en igual templanza todo el año, ni el frío molesta, ni el calor enfada, ni los rigores del invierno afligen" (113), más emociona la cadencia del buen decir que la rigurosidad científica del clima caraqueño. $\mathrm{d}$ Es un texto ficcional? ${ }_{\mathrm{C}}^{\mathrm{I} \text { Importa que lo sea? }}$

En suma, estas formas brevísimas son tan o tan poco ficcionales como cualquier texto literario. Lo que importa es lo que dicen y cómo lo dicen. Como dice Guillermo Bustamante Zamudio: "Se trata, entonces, de buena literatura breve, donde el criterio imprescindible es que sea buena" (539).

Las definiciones y caracterizaciones muy breves son tan poco concretas como las muy amplias. ¿ ¿Hay características específicas de la minificción? Sí y no, como siempre. Dependerá de la muestra, del autor, del lector.

\section{El asunto del género}

Se supone que la minificción es narrativa. Por eso muchos de sus apelativos implican el relato, o el cuento. El problema es que el relato puede estar presente en muchos géneros como la poesía y el ensayo. El otro problema es que el cuento ya no solo relata. 
Para los escritores Charles Johnson y Stuart Dybeck (Shapard y Thomas) la minificción es proteica, porque como el griego mítico cambia de forma constantemente. Des-generado lo he llamado, porque revolotea entre diversas formas escogiendo en qué género insertarse (Breve manual (ampliado) para reconocer minicuentos). Son muchos los que han vinculado la minificción con otras formas: Miguel Gomes, Guillermo Samperio y Francisca Noguerol lo vinculan con la poesía (Gomes, Samperio, y "Fronteras umbrías"). José Manuel Trabado Cabado lo llama género fronterizo por sus evidentes relaciones con lo poético. Lauro Zavala (La minificción bajo el microscopio), al hacer su catalogación de formas brevísimas incluye textos narrativos, poéticos y extraliterarios y, en "El cuento ultracorto", habla de su tendencia a la hibridación génerica, especialmente con el poema en prosa, el ensayo, la crónica y géneros de naturaleza no narrativa. Raúl Brasca en sus antologías incluye no solo textos brevísimos, sino también fragmentos de piezas literarias y no literarias. Para Taha es "intergénero" no por su vinculación con otros géneros, sino porque comparte características con éstos. Guillermo Siles lo llama un género híbrido por sus relaciones con el poema en prosa, el ensayo breve y la crónica, pero especifica que la minificción se desplaza e interactúa con otros géneros, en un proceso de relectura y apropiación de formas genéricas antiguas y modernas. Siles reconoce que todos los géneros son híbridos, pero que en la minificción la hibridez es explícita.Juan Armando Epple vincula la minificción con distintas formas simples o más librescas, y que usa uno u otro género como "simple vehículo coyuntural" (Brevísima relación 17). Para Graciela Tomassini y Stella Maris Colombo, la minificción es una clase textual transgenérica, ya que al examinar el corpus se ve que "pertenecen a una misma clase textual a pesar de su diversidad estructural" ("La minificción como clase textual transgenérica" 83). En otro artículo dicen:

Es en reconocimiento de esta complejidad que hemos aplicado a toda la clase textual de la ficción brevísima el atributo de transgenericidad. Con ello no hemos intentado cubrir con un cómodo paraguas la rica variedad de formas específicas exhibida por el corpus, sino centrar nuestra atención en la hibridez como operación transgresora y vector cultural que muestra creciente relevancia en múltiples órdenes de la realidad. ("La microficción como máquina de pensar")

Dolores Koch ("El microrrelato hispanoamericano") se refiere a su carácter de transgresor de géneros, en el sentido de que no encajan en ninguno de los géneros conocidos pero cada texto en particular puede compartir similitudes con alguno en específico. 
Creo que es evidente que la crítica considera que la minificción cabalga entre géneros, estableciéndose en aquel que quiera adoptar en un momento específico. Y si bien Lagmanovich tenía razón cuando decía que "Híbridos son todos los géneros literarios" (El microrrelato hispanoamericano 66), la minificción es específicamente des-generada. Es un texto literario que adopta las formas más variadas: cuento, relato, definición de diccionario, receta de cocina, nota periodística, ensayo, hagiografía, referencia histórica, poema en prosa, anuncio publicitario, anécdota, diálogo, las formas breves ancestrales que nombré anteriormente y cualquier forma escrita que podamos conocer. Por lo general estas apropiaciones genéticas las hace desde la ironía, la parodia y la visión alterna y el humor.

\section{¿Conclusiones?}

En algún momento dije que la minificción es un artefacto literario experimental, lúdico, intertextual, extraviado del canon, elíptico, necesario de participación (Breve manual (ampliado) para reconocer minicuentos). Es verdad, pero así es toda la buena literatura. Siempre en ella hay experimentación, juego, intertextualidad, elipse. En todo buen texto literario es necesario un lector activo y, si es posible, avezado. En las buenas expresiones literarias no hay pureza y los géneros pueden desaparecer, fundirse, entremezclarse.

De manera que la analizaremos mucho, le daremos vueltas, desentrañaremos mecanismos internos, vislumbraremos vertientes, estableceremos diferencias (a la larga el análisis literario es otro género y posiblemente uno ficcional) pero todas las características que nos parecen tan específicas quizás no lo sean: la minificción es igual que cualquier otra forma literaria, pero más corta.

\section{Obras citadas}

Andrés-Suárez, Irene. "Poligénesis del microrrelato y estatuto genérico". La huella de la clepsidra: el microrrelato en el siglo XXI. Ed. Laura Pollastri. Buenos Aires: Katatay, 2010.

Brasca, Raúl. "Criterio de selección y concepto de minificción: un derrotero de seis años y cuatro antologías". Escritos disconformes: nuevos modelos de lectura. Ed. Francisca Noguerol. Salamanca: Ediciones de la Universidad, 2004. 107-119. Impreso.

Bustamante Zamudio, Guillermo. "Ekuóreo: nuestra entrada al minicuento". La huella de la clepsidra: el microrrelato en el siglo XXI. Ed. Laura Pollastri. Buenos Aires: Katatay, 2010. 527-542. Impreso.

Colombo, Stella Maris. "Giovanni Papini: un antecedente desprestigiado". La minificción en español e inglés. Comps. Graciela Tomassini y Stella Maris Colombo. Rosario: UNR Editora/UCEL, 2011. 63-80. Impreso. 
Dávila, Paul. "Explorando el koan, la prosa antigua del zen y su aporte a la minificción actual". Manuscrito.

Epple, Juan Armando. Brevísima relación: antología del micro-cuento hispanoamericano. Santiago: Mosquito, 1990. Impreso. "Orígenes de la minificción". La era de la brevedad: el microrrelato hispánico. Actas del IV Congreso Internacional de Minificción, Universidad de Neuchâtel, 6-8 de noviembre de 2006. Coord. Irene Andrés-Suárez y Antonio Rivas. Palencia: Menoscuarto, 2006. 123-136. Impreso.

Escritos disconformes: nuevos modelos de lectura. Ed. Francisca Noguerol. Salamanca: Ediciones de la Universidad, 2004. Impreso.

Ficción súbita. Ed. Robert Shapard y James Thomas. Barcelona: Anagrama, 1989. Impreso.

"Género". Diccionario de la Real Academia de la Lengua Española. 23. ${ }^{a}$ edición. 2014. Web. 24 abril 2015.

Gomes, Miguel. "Los dominios de lo menor: modulaciones epigramáticas de la narrativa hispánica moderna". Escritos disconformes: nuevos modelos de lectura. Ed. Francisca Noguerol. Salamanca: Ediciones de la Universidad, 2004· 35-45. Impreso.

Koch, Dolores. "El micro-relato en México: Torri, Arreola, Monterroso y Avilés Fabila". Hispamérica X.30 (1981): 123-130. Impreso.

"El microrrelato hispanoamericano ¿Nuevo género?". Hostos Review 6 (2009): 103112. Impreso.

Lagmanovich, David. El microrrelato hispanoamericano. Bogotá: Universidad Pedagógica Nacional, 2007. Impreso.

El microrrelato: teoría e historia. Palencia: Menoscuarto, 2006. Impreso.

Noguerol, Francisca. "Líneas de fuga: el triunfo de los dietarios en la última narrativa en español". Ínsula: Revista de Letras y Ciencias Humanas 754 (2009): 22-26. Impreso. "Fronteras umbrías". Escritos disconformes: nuevos modelos de lectura. Ed. Francisca Noguerol. Salamanca: Ediciones de la Universidad, 2004. Impreso. "Micro-relato y posmodernidad: textos nuevos para un final de milenio". Revista Iberoamericana de Bibliografía XLVI.1-4 (1996): 49-66. Impreso.

Otxoa,Julia. "Breve entrevista a Julia Otxoa". Internacional Microcuentista, 16 septiembre 2010. Web. 24 abril 2015.

Oviedo y Baños, José. Historia de la Provincia de Venezuela. Ed. Óscar Rodríguez Ortiz. Caracas: Los libros de El Nacional, 2004. Impreso.

Perucho, Javier. El cuento jíbaro: antología del microrrelato mexicano. México: Ficticia/ Editorial Universidad Veracruzana, 2006. Impreso.

Pollastri, Laura. El límite de la palabra. Palencia: Menoscuarto, 2007. Impreso. 
Raguseo, Carla. "Twitter Fiction: Social Networking and Microfiction in 140

Characters". La minificción en español e inglés. Comp. Graciela Tomassini y Stella

Maris Colombo. Rosario: UNR Editora/UCEL, 2011. 213-220. Impreso.

Rodríguez Romero, Nana. Elementos para una teoría del minicuento. Tunja:

Universidad Pedagógica y Tecnológica de Colombia, 2007. Impreso.

Rojo, Violeta. Breve manual (ampliado) para reconocer minicuentos. Caracas:

Equinoccio, 2009. Impreso.

"La tradición de lo novísimo: libros de sentido común, libros de almohada, cajones de sastre y blogs de minificción". Brasca, et al. Minificción: tradición de lo novísimo. Quindío: Cuadernos Negros, 2010. 48-53. Impreso.

Samperio, Guillermo. "La ficción breve". Escritos disconformes: nuevos modelos de lectura. Ed. Francisca Noguerol. Salamanca: Ediciones de la Universidad, 2004. 65-7o. Impreso.

Siles, Guillermo. El microrrelato hispanoamericano: la formación de un género en el siglo $X X$. Buenos Aires: Corregidor, 2007. Impreso.

Taha, Ibrahim. "La semiótica de las ficciones minimalistas". Poéticas del microrrelato. Comp. David Roas. Madrid: Arco, 2010. 255-272. Impreso.

Tomassini, Graciela. "Ambrose Bierce, el Diablo y el microrrelato hispanoamericano". La pluma y el bisturí: actas del 1. er Encuentro Nacional de Microficción. Ed. Sandra Bianchi, Raúl Brasca y Luisa Valenzuela. Buenos Aires: Catálogos, 2008. 353-364. Impreso.

"Escrituras privadas: un hilo secreto en la trama de la minificción". La minificción en español e inglés. Comp. Graciela Tomassini y Stella Maris Colombo. Rosario: UNR Editora/UCEL, 2011. 241-255. Impreso.

__ y Stella Maris Colombo. "La minificción como clase textual transgenérica". Revista Iberoamericana de Bibliografía XLVI.1-4 (1996): 79-93. Impreso.

__ y Stella Maris Colombo. "La microficción como máquina de pensar". El cuento en red 28 (2013): 30-42. Web. 2014.

Trabado Cabado, José Manuel. "El microrrelato como género fronterizo". Comp. David Roas. Poéticas del microrrelato. Madrid: Arco, 2010. 113-131. Impreso.

Zambrano Yánez, Francys. "Interrelaciones entre las plataformas sociales y las formas literarias: Twitter y la minificción". Tesis para optar a la Licenciatura en Letras. Universidad Católica Andrés Bello, Caracas, 2013.

Zavala, Lauro. "El cuento ultracorto: hacia un nuevo canon literario". Revista Iberoamericana de Bibliografía XLVI. 1-4 (1996): 67-78. Impreso.

_L La minificción bajo el microscopio. Bogotá: Universidad Pedagógica Nacional, 2004. Impreso. 